\title{
Estúdios de pintura e os usos da fotografia pela estética e pela didática em pintura
}

ph cavallari ${ }^{1}$

1 Pedro Henrique Villi Cavallari é graduado em Artes Visuais pela Universidade Estadual de Maringá (PR), especializado em História e Cultura Afro-Brasileira e Indígena pelo Centro Universitário Internacional, mestrando em Artes Visuais na linha de Ensino de Artes Visuais pela Universidade do Estado de Santa Catarina e participante do grupo de estudos e estúdio de pintura Apotheke. Artista visual, músico compositor, pesquisador e professor de arte pelo Colégio SESI Internacional de Curitiba. Se interessa por desenho, pintura, música, gravura, escultura, literatura, estética, fenomenologia, filosofia da linguagem, filosofia da educação e antropologia da arte.

Lattes: http://lattes.cnpq.br/9199191395094333

E-mail: ph.cavallari@yahoo.com 
Aplicar perigosamente a expressão usar a fotografia pode incorrer em mal entendido, como se esta fosse simplesmente uma ferramenta que cumprisse seu papel mecânico, físico-químico, registro luminoso dos quais nasceriam frias querelas de uma presença e uma existência passadas. Bem entendida, a foto vai além. Por motivo de sua mecânica que resulta em formas, tem dimensão estética que poderá ser tão significante quanto a experiência que cada indivíduo tem com ela.

Acompanhando Ostrower (1998), formas "são configurações de alguma matéria, quer seja física ou mental. [...] As linguagens artísticas se constituem de formas [...]. $\mathrm{Na}$ arte, forma e matéria são inseparáveis" (p. 257). Seriam as artes explorações da forma por meio dos sentidos para mover matéria, como a fotográfica, por exemplo. Da luz à escritura, da e pela luz, a fotografia enquanto linguagem artística está aí para ser usada, para constituir formas, sejam experimentais, sejam documentais. Mas flertar com os limites da profanação ao dizer sobre os usos uma arte, uma práxis que, para alguém, representa o sustento, ou para outrem a sua linguagem artística, sem ser desonesto, só pode acompanhar um profundo desejo de levantar o questionamento sobre fotografia e arte educação, que acompanha o tema deste primeiro volume do sexto ano da Revista Apotheke (Fotografia e arte educação: da permanência à fluidez), acompanha também a questão de como a linguagem tem sido usada no processo de minha pesquisa de mestrado (PPGAV/UDESC). Usar é mais um dos sentidos verbais inerentes à fotografia e se pudermos traçar seguramente, para além das fronteiras frágeis da fruição estética pura, um uso da linguagem fotográfica que fosse prioritariamente emancipatório, diremos que é o que pode ser promovido pela educação.

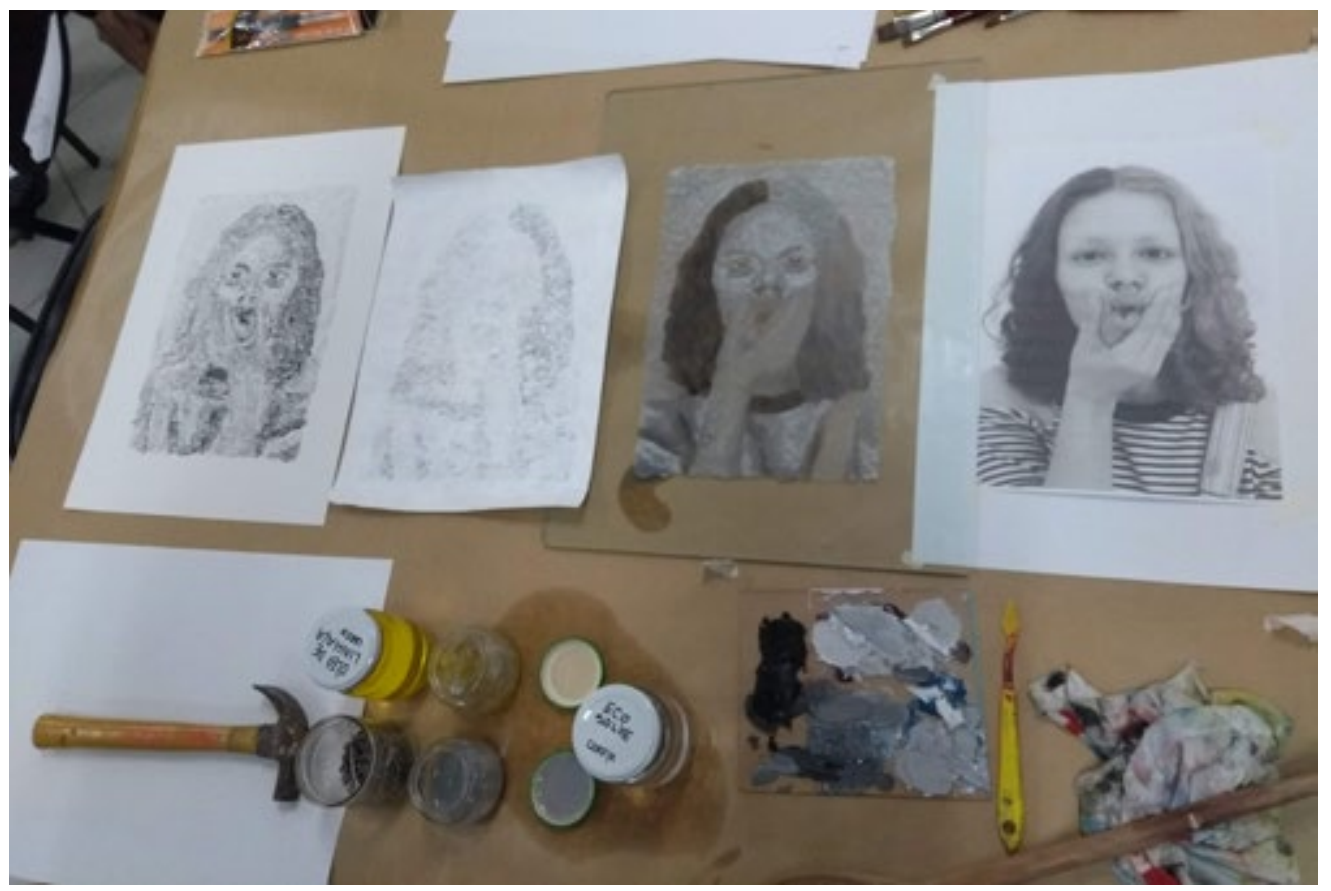

Fig. 1: Auto-retratos por monotipia, impressão fotográfica, materiais e mesa de trabalho. Giovana Coppola. Aula da disciplina Processo Pictórico (DAV/UDESC 2019/2), coordenação Prof.a Dr.a Jociele Lampert. Foto: ph cavallari. Reprodução autorizada pela autora. 
Seja no ensino de fotografia ou por meio ela, o uso didático da mesma alimenta o aparato visual, um campo importante da arte-educação que deve ser enriquecido com imagens construídas, pensadas, desconstruídas e repensadas pelos estudantes sobre como se constitui a imagem, em meio ao fim emancipatório da passividade receptiva frente ao universo imagético turbulento e intencionado pelas mídias atuais. Esta tarefa se dará pela união da reflexão e do fazer imagéticos, ou como coloca Dewey (2010) como uma experiência singular, que une fazer e pensar, e é unida de ponta a ponta pelas ilações estéticas que o sujeito envolvido na experiência - neste caso o processo formativo - poderá traçar enquanto ser senciente. No caso da pintura e do ensino de pintura, por exemplos, fotografias instauram possibilidades referenciais e metodológicas pois compõem, em maior escala, o processo de instauração da imagem pictórica como pontos de partida, notas de memória, dados para análise ou meio de veiculação. Como afirma Dewey, não há divisões limítrofes na experiência singular, destarte, a fotografia está unida ao todo do processo pictórico, além de ser objeto estético que aqui referencia outros objetos estéticos.

Não há funcionalidade fotográfica isolada. Lembramos que, segundo a definição de Duarte Jr. (2009) sobre objetos estéticos e práticos, o mesmo objeto pode comungar ambas funções, como uma caneta, que pode ser boa para escrever e agradar aos olhos e ao toque. A fotografia em meio a aula de arte é uma linguagem estética e também uma ferramenta, pois por ela se pratica a comunicabilidade do registro para a memória (humana e digital), bem como a ponte para por outras linguagens em ação. A foto é dado proveniente dos acontecimentos e, ainda que não prove a dinâmica dos fatos por sua inerente parcialidade do espectro luminoso estático, poderá ser fértil às inflexões e reflexões posteriores, como componentes da pesquisa em arte. Os sentidos permanente e fluido da fotografia têm consequências nos modos de formar: da prática de registro das cenas que compõem os processos formativo e didático; da retro referencialidade entre as formas estéticas. Poderá compor o campo de significação das narrativas sobre o processo, bem como novas formas, novos trabalhos.

Permanência e fluidez de um documento fotográfico se encerram nas suas funções prática e estética. Enquanto permanência da memória a foto é um documento visual que a depender do contexto da pesquisa, poderá ser muito fértil a título de referência direta ou indireta, ainda que não totalize o momento vivido. Enquanto estética a foto projeta relações fluidas sob o olhar de cada um, pois ativa de modo particular significações de caráter estético. Neste sentido Ostrower (1998) considera que, na dinâmica do processo formativo,

\footnotetext{
"a memória desempenha um papel essencialmente conservador e também determinista, sua função sendo a de preservar a continuidade e a coerência da identidade da pessoa nas diversas fases de desenvolvimento e transformação." (p. 64)
}

Acompanhando Ostrower (1998, p. 75) a memória é "dinâmica", pois ao mesmo tempo em que conserva a identidade, projeta-se na transformação e no 
desenvolvimento, enquanto parte do processo formativo. Entre 2019 e 2020 tenho participado e ministrado aulas em estúdios de pintura na Universidade do Estado de Santa Catarina e no Colégio SESI Internacional de Curitiba, componentes do Programa de Pós-Graduação em Artes Visuais (CEART/UDESC), do Grupo de Estudos e Estúdio de Pintura Apotheke (UDESC/CNPq) e da docência pela rede SESI-PR (FIEPR) de educação básica. Nestas aulas temos lidado constantemente com a fotografia com propriedades dinâmicas que permanecem e também fluem. A microprática de monotipia com tinta óleo na disciplina Processo pictórico para o curso de Artes visuais (DAV/UDESC 2019/2) perpassa dois ou mais sentidos da fotografia. No auto-retrato de uma pintora (Fig. 1), ela reorganiza forma e cor a partir do retrato impresso visto através da placa de acetato. Ao usar tinta óleo sobre esta matriz transparente, experimenta impressões em sequência para obter resultados variados. As evidências do trabalho são resguardadas pela fotografia digital. Sua projeção luminosa sobre uma tela (Fig. 2) auxilia o aluno do Painting Studio (CSI/ SESI-PR/FIEPR) no aproveitamento da estrutura formal de um esboço planejado por colagem então fotografada. Frames cinematográficos abandonados há meses podem embasar um novo estudo de monocromia ou bicromia (Fig. 3). Aqui o instrumento fotográfico fundamenta a pesquisa como ação primordial ao trabalho analítico. Um professor poderá projetar um exemplo fotográfico de exercício pictórico (Fig. 4). Fotografias são dados da pesquisa e como partes de seu todo a retroalimentam e compõem seu campo fenomenal. Objetos estéticos componentes da experiência singular de um processo de pesquisa em arte.

Pesquisar em arte, como sustenta Rey (2002), é traçar todo tipo de perfilamento de uma ou mais formas de narrar em processo. O pesquisador em arte não estabelece contornos rígidos em volta da linguagem central de seu trabalho em desenvolvimento, como se tivesse o dever em ser fiel à sua arte (linguagem artística). Ao contrário: poderá buscar agregar quantas possíveis formas de descrever, teorizar e poetizar sobre o tema, e também sobre a própria linguagem em questão. Formas experimentais de epistemologia de pesquisa em arte: poemas, notas, frases, resultados, fotografias, esboços, rabiscos, caminhadas, cafés, conversas, partes do processo são o processo por composição, são modos epistemológicos da pesquisa em arte, pois a põem em movimento quando passam de componentes possíveis do processo para formas atuais (formatividade).

A metodologia de pesquisa em arte apruma meu trabalho em pintura e didática em pintura, constantemente em contato com o registro visual pela fotografia, tanto como principal instrumento para coleta de dados, conjuntamente às notas em diário formativo, quanto como parte integrante do exercício pictórico, quando esta linguagem se encontra alinhada a outras tecnologias da informação, como a projeção luminosa, digitalização e impressão gráficas, componentes do processo pictórico. Proponho pelo projeto de pesquisa um olhar sobre a importância do espaço pictural do estúdio como campo fenomenal para a experiência estética, o que faz as ações de pesquisa que acontecem no espaço interior do estúdio, e a fotografia destes espaços, dados componentes da pesquisa em arte. 


\section{Revista Apotheke}

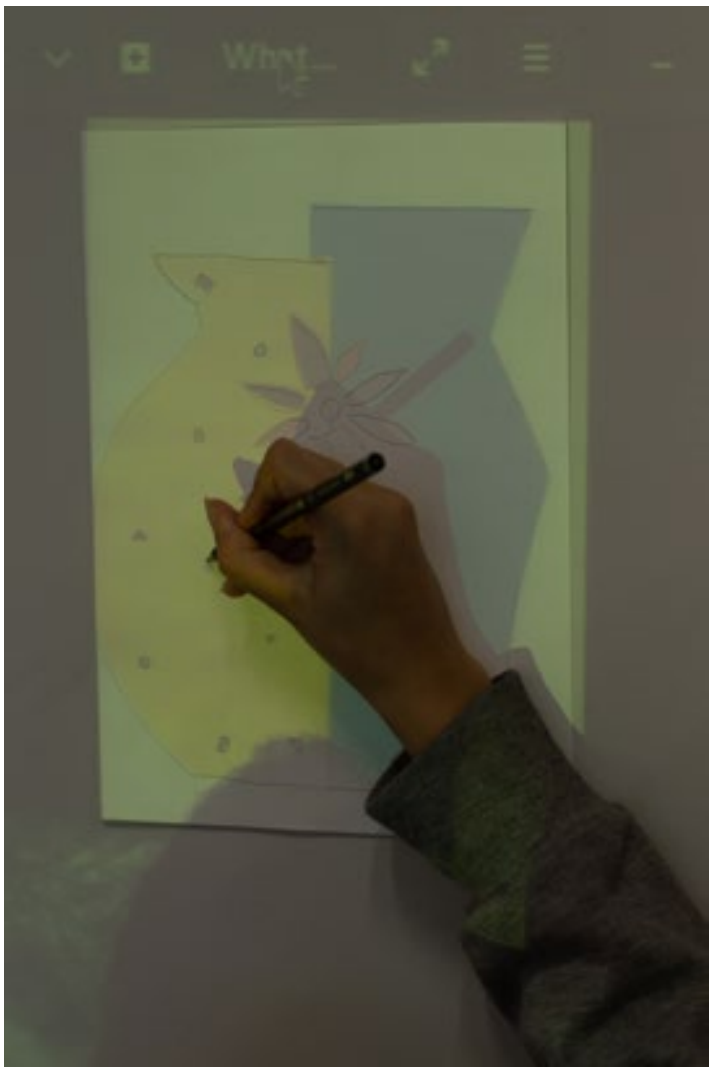

Fig. 2: Fotografia digital projetada em tela. Painting Studio, Colégio SESI Internacional de Curitiba (FIEPR), coordenação Prof. Esp. Pedro Henrique Cavallari. Foto: Luca Pasquali.

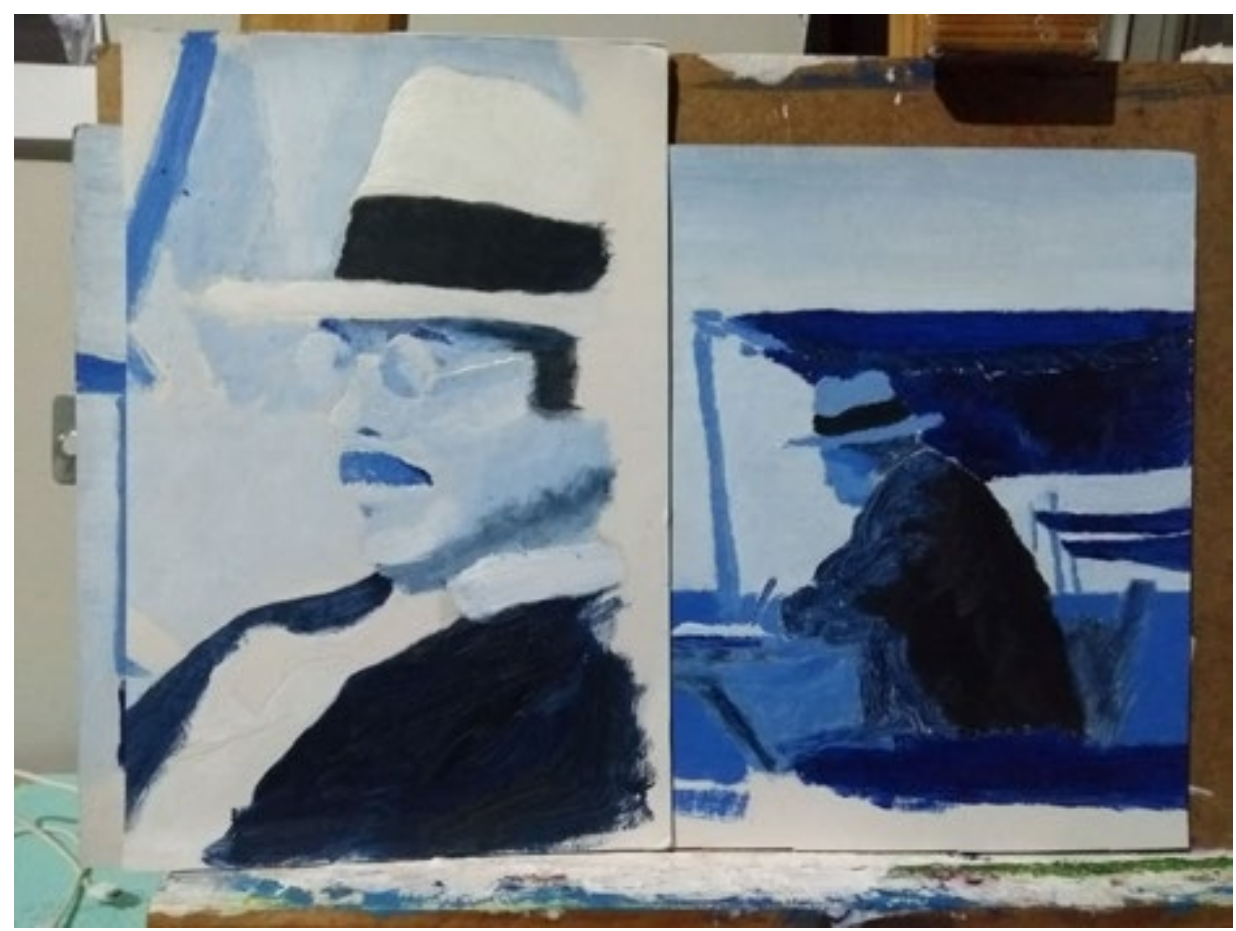

Fig. 3: Monocromia a partir de fotogramas de A Morte em Veneza (Luchino Visconti, 1971). ph cavallari. Óleo sobre cartão. 2020. 


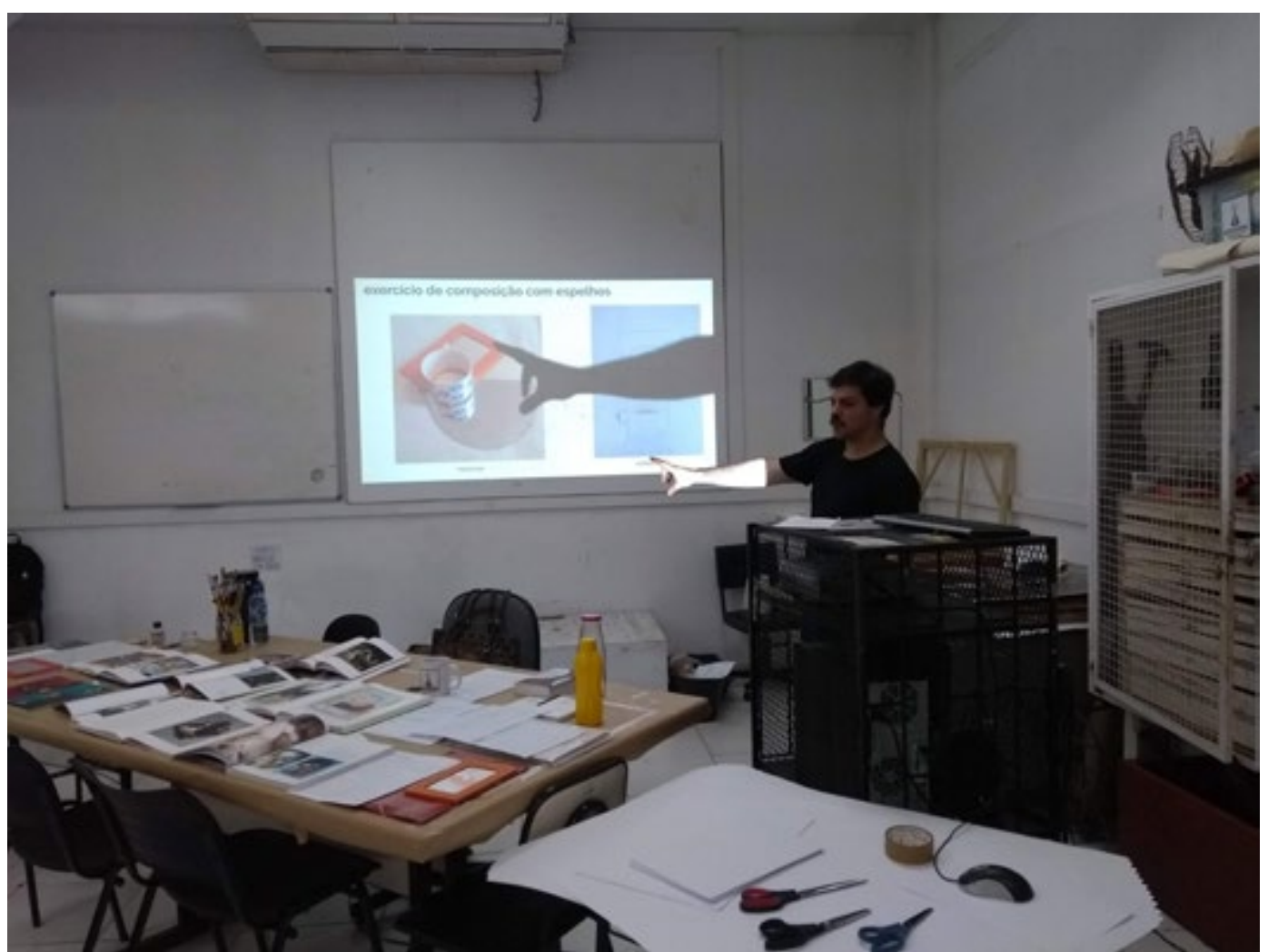

Fig. 4: Exemplos fotográficos sobre figuração e objeto espelho em projeção luminosa. ph cavallari. Aula da disciplina Processo Pictórico (DAV/UDESC 2019/2), coordenação Prof.a Dr.a Jociele Lampert. Foto: William Silva.

O espaço pictural, que também é fotográfico, faz fotografia e pintura interagirem (Fig.s 4 e 5) porque compõe o campo de significação da pesquisa. $O$ conceito de campo fenomenal (ou campo de significação) remonta à fenomenologia na leitura que os filósofos franceses fundadores do existencialismo, em especial Merleau-Ponty, articularam com a filosofia de Edmund Husserl (1889-1938).

O campo fenomenal é para onde se abre a percepção em meio à experiência. O fundo sob a figura que poderá ser significada. Para a percepção, a coisa percebida no espaço. É essencialmente importante o papel da percepção no existencialismo, campo da filosofia que a religa com o conhecimento do ser, numa releitura da teoria da Gestalt e da fenomenologia. Segundo Merleau-Ponty (1991) há um primado da percepção, em relação à cognição ou ao intelecto, e é importante acompanhar a percepção para entender os fenômenos. A Ciência é um desdobramento da percepção que visa compreender as coisas, muitas vezes, ambiciosamente compreender ao todo. Esta totalização é criticada por Merleau-Ponty (2006), que resguarda na percepção a irredutibilidade das coisas a meras definições, deslocando a redução eidética husserliana da ideia transcendental, ao retorno às coisas mesmas. Estas, irredutíveis a não ser a si mesmas, não cessam em ser descritas pela linguagem e pela consciência que as recebe por via da percepção, bem entendido, pelo corpo. A percepção do corpo próprio e do outro são os modos primordiais da fenomenologia da percepção, pela qual o mesmo filósofo (2012) dirá que a pintura opera na mesma 
ordem de fenômenos, de modo a unir matéria e espírito na medida em que dá forma pelo ato pictórico. O gesto do pintor é semelhante ao ato de fala. Para Merleau-Ponty (2006) perceber, pintar e falar se dão por união do percebido com a porção de conhecimento do campo em que se apresentam os fenômenos (campo fenomenal) e que dá condição ao perceber, presente no momento em que a pintura toma forma. $\bigcirc$ mesmo se dá com a fala sob o fundo de linguagem ou com a composição fotográfica pelo enquadramento sobre a espacialidade vivida.

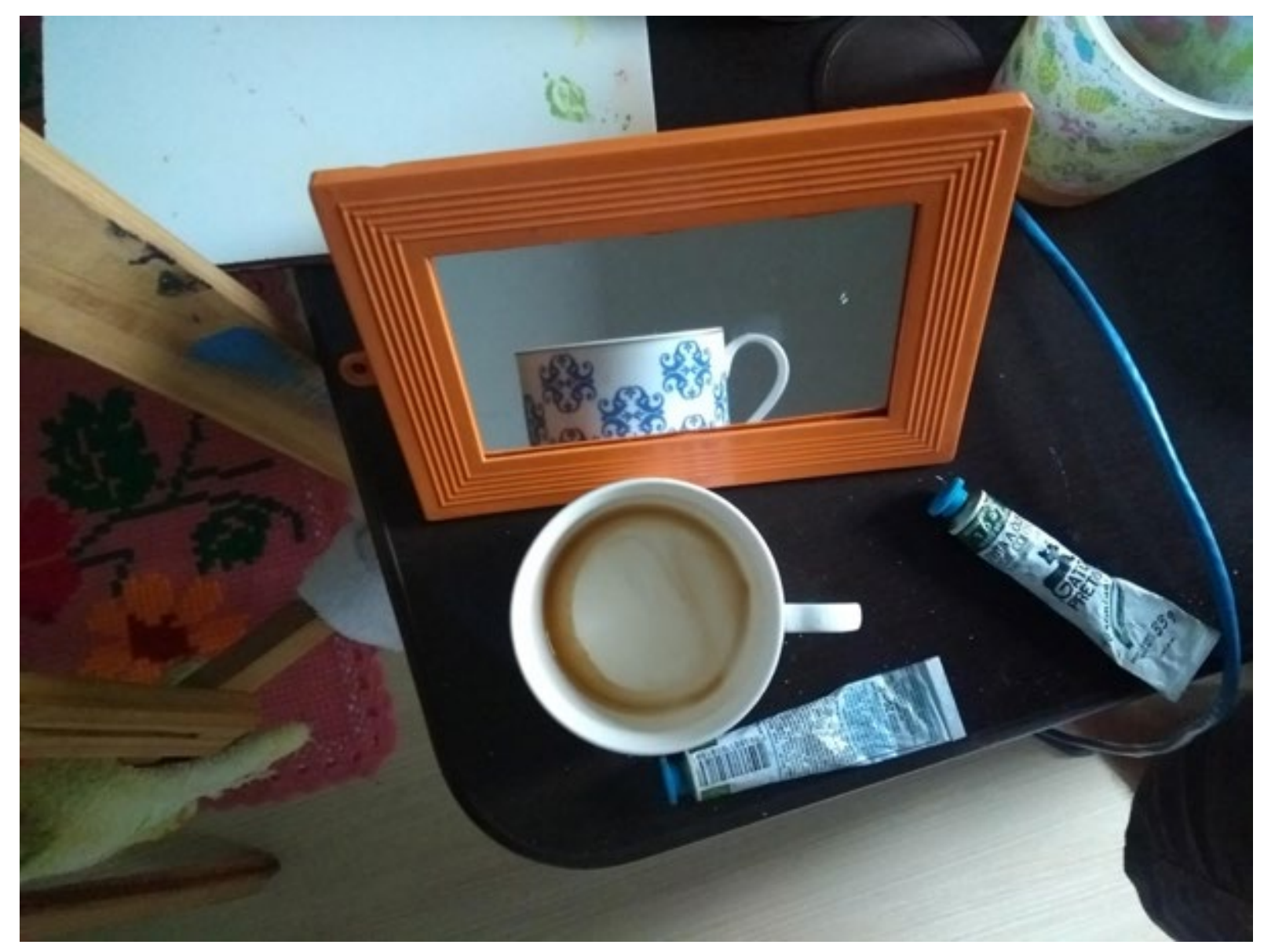

Fig. 5: Estudo de objetos em figuração/esboço/exemplo para proposição didática de Processo Pictórico sobre figuração e objeto espelho; Mesa de trabalho com objetos pessoais. Foto: ph cavallari. Acervo do artista.

Mas o obturador se diferencia da visão que é dupla. $\bigcirc$ ponto focal da câmera é menos dinâmico que a visão, pois os olhos não cessam do movimento. MerleauPonty (2013) considera que a percepção, ainda que instrumentalizada, atua no corpo, integrado inclusive pelo instrumental. O campo fenomenal tem conformidade com a gestalt, como aponta Ostrower (1998, p. 76), na qual "não existe a noção de totalidade ou partes, isoladamente. São estados de relacionamentos. Pois as totalidades podem modificar-se a qualquer instante através de novos relacionamentos" com o campo, do qual se afasta a ideia de todo no qual se vê a parte, pois esta relação se dá pela estrutura figura/fundo, mediante a qual poderá se inverter. Percebe-se as diferenças de volume entre a foto (Fig. 5) da composição e a pintura direta do objeto percebido 
(Fig. 6) pelo que há entre instrumento fotográfico e os olhos. Chamaria este entre de campo fenomenal se daí tiro uma relação comparativa de mão dupla.

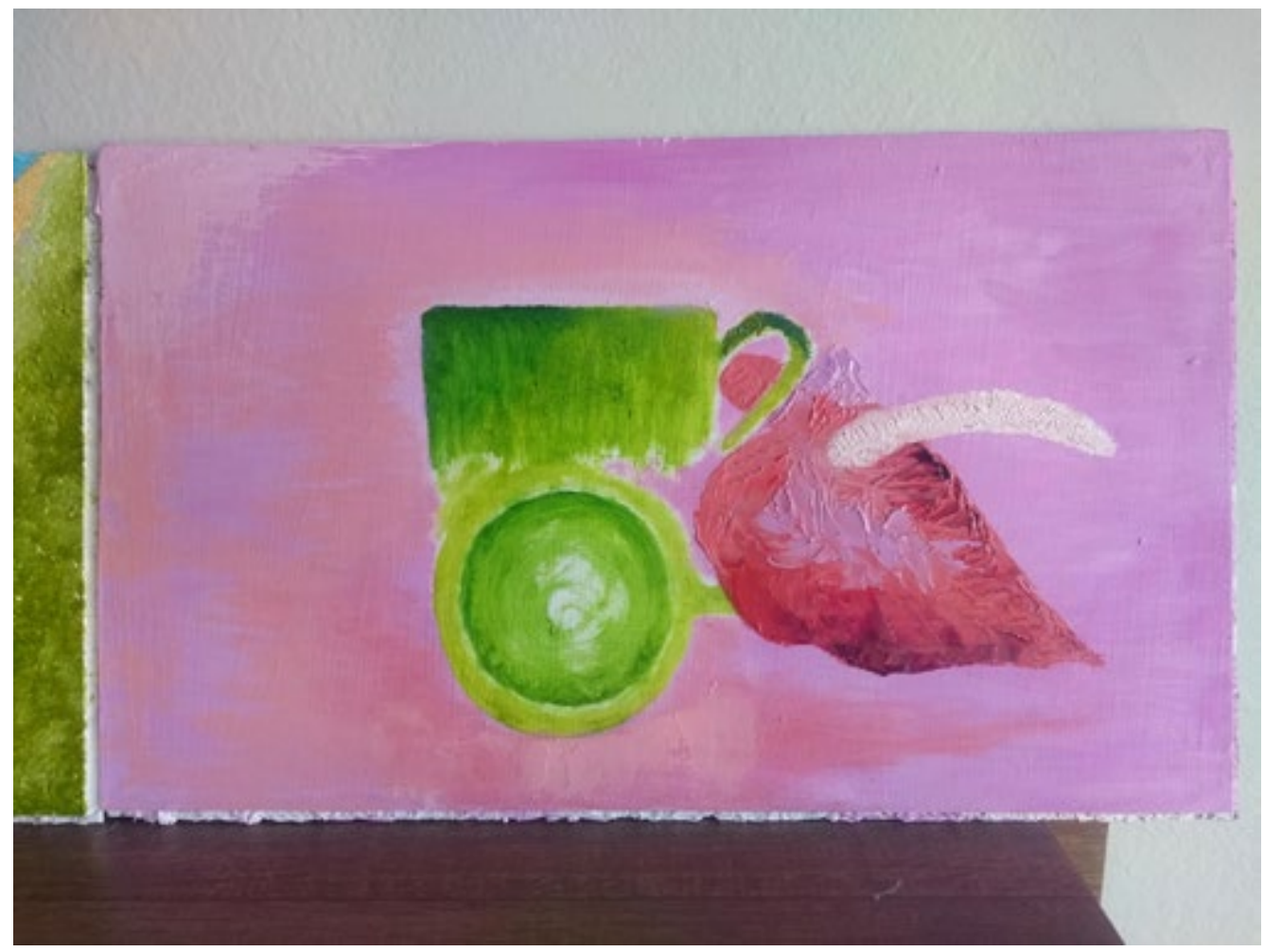

Fig. 6: Composição com antúrio e xícara. Óleo sober madeira. ph cavallari. Acervo pessoal.

Já no estúdio de pintura há um fundo de experiência presencial e de pintura sobre o qual aparecem os modos de formar pintura, e também faz sentido a fotografia produzida neste espaço-tempo como permanência ou persistência da memória. Por dentro dos modos de pintar está a linguagem fotográfica que também dá condição à pintura que se instaura e às experiências estéticas consequentes. No sentido Deweyano a experiência estética permeia toda a dimensão sensível do trabalho, toda parte que tenha a ver com qualidades organizadas de modo a tomar forma, assim como se espera da pesquisa em arte.

Não obstante, a experiência em si tem um caráter emocional satisfatório, porque possui integração interna e um desfecho atingido por meio de um movimento ordeiro e organizado. Essa estrutura artística pode ser sentida de imediato. Nessa medida é estética (DEWEY, 2010, p. 116)

Na medida em que a experiência fotográfica no interior do estúdio pictural e de minha pesquisa pictórica se constitui por caracteres qualitativos organizados, se constitui como estética. Com a finalidade de pensar a importância do espaço pictorial para a experiência estética ligada a pintura tenho lidado com a questão de quais são as implicações na arte-educação e do ensino de pintura pelo uso da fotografia, pois este ultrapassa a noção de dado de pesquisa, passando a habitar o processo como um dos eixos centrais do trabalho. Como já mencionado, o tratamento desse questionamento se dá atualmente por pesquisa em arte e tem gerado pintura e 
discussões sobre o tema. Muitas destas conversas se deram junto a Miguel Vassali e William Silva, companheiros do Grupo de Estudos e Estúdio de Pintura Apotheke, e seminário temático Fotografia como representação social moderna (PPGAV/UDESC 2019/2), aos quais deixo aqui meu agradecimento.

Agradecimentos também devo aos apoios de Lucca Pasquali, José Carlos da Rocha e Rebecca Kaled na documentação fotográfica dos processos didáticos, que tem rendido belas imagens, construídas não aquém do senso estético destes artistas.

\section{Referências}

DEWEY, John. Arte como experiência. São Paulo, SP: Martins Fontes, 2010.

DUARTE JR, João Francisco. O que é beleza?. São Paulo, SP: Brasiliense, 2009

MERLEAU-PONTY, Maurice. A Prosa do Mundo. São Paulo, SP: Cosac \& Naif, 2012.

Fenomenologia da percepção. São Paulo, SP: Martins Fontes, 2006.

O olho e o espírito. São Paulo, SP: Cosac \& Naif, 2013.

O primado da percepção e suas consequências filosóficas. São

Paulo, SP: Papirus, 1991.

OSTROWER, Fayga. Sensibilidade do Intelecto. Rio de Janeiro, RJ: Elsevier, 1998.

REY, Sandra. Por uma abordagem metodológica da pesquisa em artes visuais. In: BRITES, Blanca; TESLER, Elida (Orgs.). O meio como ponto zero: metodologia de pesquisa em Artes Plásticas. Porto Alegre: UFRGS, 2002. (pp. 123-140). 